\title{
A Collaborative Approach to Care Coordination: Maccabi
}

\author{
case study \\ Pavel Kubü ${ }^{1}$, Rachelle Kaye ${ }^{2}$, Mariana Waksman ${ }^{1}$, Mark N. Blatt ${ }^{1}$, Tony Corrigan ${ }^{1}$ \\ ${ }^{1}$ Intel Corporation \\ ${ }^{2}$ Maccabi Healthcare Services
}

\begin{abstract}
Cost pressures, new payment models, and demographic trends are creating a global economic crisis as health systems struggle to care for an aging population of sicker patients. Funds available for healthcare are constrained, and they're being wasted by inefficient, uncoordinated healthcare services. Reflecting the importance of collaboration in caring for patients with chronic conditions, nearly 80 percent of the scoring criteria for the National Committee for Quality Assurance's (NCQA) Recognition Program for Physician Practice Connections (PPC) Patient-Centered Medical Home (PCMH) relate to information sharing and teamwork. New payment models are forcing delivery networks to share the risks and potential cost savings of caring for these patients.
\end{abstract}

\section{Correspondence to:}

Pavel Kubů

Intel Czech Tradings, Inc.

Address: Pobřežní ulice 620/3, 18600 Prague

E-mail: pavel.kubu@intel.com
By imposing direct or indirect financial consequences, these models incentivize organizations to emphasize prevention, deliver care in the lowest-cost appropriate setting, and reduce readmissions, Emergency Department (ED) visits, acute-care admissions, and bed days of care. Maccabi's core belief is that all IT investments are business investments that should support strategic priorities and deliver a sustainable advantage to the organization. Among other clinical benefits of collaborative approach to care coordination in Maccabi implementation of Health IT tools supporting care coordination resulted in $13 \%$ increase in the number of diabetic patients who had a regular $\mathrm{HbA} 1 \mathrm{c}$ and $8 \%$ increase in the number of diabetic patients whose $\mathrm{HbAlc}$ results indicated that the disease was stable.

\section{Keywords}

\section{EJBI 2014; 10(2):8-11}

received: July 28, 2013

accepted: March 9, 2014

published: March 31, 2014

\section{Introduction}

The leadership of Maccabi concluded in 1983 that the healthcare IT system of the future would require sophisticated information and communication technology for efficient management of the healthcare system, as well as effective and innovative healthcare IT services delivery. Maccabi leadership also recognized the need for top management to be hands-on, solve problems and commit resources to the project. In 1990, implementation of the Electronic Health Records (EHR) system began.

Across the nations of the OECD, health expenditures consume an average of 9 percent of Gross Domestic Product, and real per capita healthcare expenditures grew more than $4 \%$ annually during 1997-2007.1 In the UK, the NHS wastes GBP 330 annually by treating patients as emergency hospital admissions when they could be seen by their GP.2

An oft-cited study shows that in the U.S. in 2003-2004, almost one in five hospitalizations of Medicare fee-for- service patients resulted in a readmission within 30 days of discharge; three-quarters of these could have been prevented by better coordinated care, and the cost to Medicare for these readmissions was USD 15 billion.3 Even traditional fee-for-service practitioners are under financial duress, with the U.S. Small Business Administration reporting that SBA-backed loans to physicians' offices grew more than tenfold from 2000 to 2011.4

Controlling costs starts with better management of patients with multiple chronic diseases, and it puts a premium on coordination and collaboration. Medicare patients with multiple chronic illnesses see an average of 13 different physicians in the course of a year, 5 and their full treatment team can easily include another dozen professionals and paraprofessionals.

Maccabi invested in health information technology (HIT) even though there was a lack of empirical and quantitative evidence regarding return on investment back in nineties, particularly in the area of cost containment. Establishing a governance structure for the development and 
management of the IT system was a key success factor in that it provided integrated responsibility and accountability amongst stakeholders. Clearly identifying concrete needs and goals provided direction to the Maccabi leadership and enabled focus on particular solutions to clinical problems. This process helps to establish standardized workflows and a platform to build on as understanding improves and increased integration of care becomes possible.

\section{A collaborative process}

The Maccabi ICT systems are designed to serve independent contractors, doctors and health care providers. Maccabi had to adapt to their needs and work flows instead of expecting them to adapt to the new system Maccabi created. Maccabi's success in adapting to ICT-based health delivery is based on stimulating and promoting collaboration with strategic partners both nationally and internationally, particularly in the areas of:

- ICT in healthcare

- Managing chronic disease and care of the elderly

- Economic analysis and research

- Telemedicine

- Mobile health

\subsection{Incentivizing members}

To incentivize end users and members, Maccabi issued a health ID card to all its members, to be presented at every point of service, thereby enabling the system to capture all of the members' transactions with the healthcare delivery system. From 2001 and on, Maccabi patients had access to their own medical information (via kiosks, web portal and mobile devices) - much of what was available to the doctor was made available to the patient including doctor visits, test results, medications prescribed, feedback on risk factors, as well as online guidance for chronic disease management and health promotion. Maccabi members also benefit from knowing that their complete health record is available wherever they engage with the health system enabling fast and accurate care delivery.

\subsection{Incentivizing physicians to participate}

Successful health IT investments are characterized by the willingness of physicians to engage in new processes and to make changes in the way they work. Clinician barriers such as high initial costs, uncertain financial benefits, investments in time, difficulties with technology and lack of integration with other care services can undermine any health IT initiative. Maccabi addressed these issues by providing incentives for meeting organizational objectives that are embedded into ongoing organizational pro- cesses. One of the reasons that there was such rapid uptake among the doctors was that Maccabi offered financial incentives and simultaneously reduced the financial burden of computerization. Incentives included a two percent increase in quarterly capitation fees, negotiating significant group discounts on the purchase of hardware, providing interest-free loans for purchasing hardware with convenient repayment conditions, and providing the software at no charge to the physician. The uptake of the EHR was gradual, beginning with doctors who volunteered to pilot the system. After a successful pilot stage, it was agreed that using the EHR would be voluntary for doctors currently under contract but mandatory for new doctors. This continued until the majority of doctors were in the system, at which point it became a condition of 'doing business' in Maccabi.

\section{Mobilizing and empowering the ecosystem}

\subsection{Kiosks}

Maccabi provides kiosks at all of its branches and the major government hospitals. The kiosks increase the accessibility of personal medical information and empower the member. Kiosks provide self-service medical information services similar to those at Maccabi online.

\subsection{The Maccabi Hotline and customer relations management (CRM) center}

Maccabi has established a 24 hour a day, seven days a week call center to provide around the clock services to its members. This consists of informationon all services, including who is actually receiving patients at the time of the member's inquiry, information on member privileges and benefits, making appointments, and telephone consultation with a nurse and/or physician. In order to make this service even more responsive to members' needs, a new CRM program has been installed, which enables the customer agent to see relevant member information, so that he can provide personally tailored service on the spot. The system also records all encounters. It is also being installed in all of Maccabi's anch offices and will operate in a totally integrated fashion nationwide.The encounter with the nurse can also occur through video conference.

\subsection{Patient portal self-management}

Maccabi has transformed its information system into a tool for patient collaboration, education and communication predominantly via a secured patient internet site that can be accessed by the Maccabi member. The member receives their own unique user name and password which grants access to their own information and provides tools 
to review medical records, access medical information and receive individual medical feedback.

The patient can manage his medical records in this website, can scan documents from other sources and enter measurements he takes himself, such as blood pressure. As a result, the entire health record is in one place. These computer-based tools and services save members unnecessary trips to Maccabi offices and allow members to perform numerous online activities from their homes, including scheduling appointments, purchasing travel insurance, modifying personal details and automatic billing through members' bank accounts.

\section{Initial Benefits for Patients and Physicians}

In Maccabi, the physician was able to perceive four benefits within a very short time after implementation:

- The insertion of the member health ID card into the physician's computer automatically populated the screen with the patient's demographic information, saving the physician time in writing or entering the information

- The insertion of the membership card and the validated authentication details of the clinician generated an online connection to the Maccabi database. The clinician could then verify the patient's eligibility to receive services, guaranteeing that the doctor would be paid for the visit

- The initial screen presented the doctor with a summary of the medical information on the patient, including major problems, diagnoses, allergies and medications

- Once the doctor entered a diagnosis for the visit, the information was transmitted and the claims adjudication process was initiated, saving additional entry and paperwork for billing

\subsection{Optimized processes}

Financial savings have and continue to be realized primarily through optimized processes that take advantage of shared electronic health records. Less time is spent in administration and more on care delivery. Physicians have been able to eliminate their use of transcription services, which has contributed substantially to paying for use of the EHR

\subsection{Avoiding adverse drug events}

One of the most common types of medical error is the adverse drug event. Maccabi's use of ICT and decision support systems has significantly reduced the potential for a patient to have an adverse reaction from being administered an inappropriate medication. For example the laboratory reporting system was modified to provide physician alerts regarding potassium testing. A nightly batch file checked pharmacy diuretic purchases against the patient's potassium blood test status. On-screen computergenerated reminders were sent to physicians of patients lacking a recent potassium test. Reminders to physicians increased potassium testing by 9.8 percent.

As the system has become more sophisticated, more benefits have been realized. For example, in evaluating the effect of online prescription screening in community pharmacies and physician offices for Maccabi, it was found that computerized prescription entry coupled with drug interaction screening software in the community caused a 62.8 percent reduction in pharmacy-dispensed prescriptions with severe drug interactions.

\subsection{Duplicate lab test}

The accuracy of the health record minimizes waste within Maccabi, for example unnecessary laboratory tests. Prior to the introduction of the health record, physicians would often have an incomplete patient history and consequently may not know what previous diagnoses have been made. Consequently physicians would potentially order inappropriate tests or tests that were unnecessary. When Maccabi introduced the decision support system, it took just two months to observe a 35 percent reduction in ordering of lab tests.

\subsection{Covered patients}

Identifying which patients presenting at clinics are Maccabi patients is important for physicians in order that they can be appropriately reimbursed. By using the magnetic card, it has become simple for physicians to instantly identify the patient and also to access their health record, saving time and ensuring payment.

\subsection{Administrative savings}

Maccabi members have access to their health record online. Maccabi provide web and mobile access to test results, appointments and general information on-demand to members. By enabling members to service their own information needs, Maccabi benefits from reduced administrative costs.

\subsection{On-site dispensing}

The EHR has enabled Maccabi to contract 700 private pharmacies in addition to its own 53, to directly service the needs of its members. Physicians save nonrevenue generating time dealing with pharmaceutical issues, such as contra-indications. There is no need to phone or fax inquiries due to illegible handwriting or obtaining autho- 
rization for refills. Significant benefits have been realized from on-site dispensing and promoting this to Maccabi members.

\section{Coordinated Care realizes Clinical and Economic Benefits}

Over a three year period to 2009, Maccabi achieved the following results:

- 17 percent increase in the number of women above age 50 who had a breast exam with mammography

- 17 percent increase in the number of members over 65 who received a pneumovax vaccination

- 13 percent increase in the number of diabetic patients who had a regular $\mathrm{HbA1c}$

- 8 percent increase in the number of diabetic patients whose $\mathrm{HbA} 1 \mathrm{c}$ results indicated that the disease was stable

Maccabi can control the prescribing of drugs centrally, so that physicians are directed to the most cost effective and appropriate drugs. In 2001, medical policy encouraged the use of statin drugs for treatment of high cholesterol. Now when lab results showing high cholesterol arrive electronically in a doctor's computer, the decision support system asks if he wishes to prescribe a statin drug. Maccabi can designate a preferred drug, which the physician is directed towards. Despite the very impressive increase in the overall number of patients receiving statin therapy resulting in healthier patients (lowered LDL levels), because of the use of the Maccabi preferred drug,
Maccabi actually realized a very significant decrease in drug expenditures for statins. The amount saved, for the years 2004-2006 was $\$ 5$ million USD in statin drug expenditures. In addition, due to the improvement in patient outcomes and reduced complications, the average hospital stay for this cohort declined from 0.7 days in 2000 to 0.5 days in2006. This amounts to 76,000 avoided hospitals days with a cost savings of $\$ 32$ million USD.

Despite an increase in the number of patients taking statins, the use of the preferred drug resulted in a decrease in drug expenditures for statins. The cost saving in expenditures on statin drugs among patients with cardiovascular disease, for 2004 - 2006 alone, was $\$ 5$ million USD.

\section{References}

[1] OECD Health Data 2009. www.oecd.org/health/healthdata.

[2] Ian Blunt, Martin Bardsley and Jennifer Dixon, Trends in Emergency Admissions in England, 2004-2009. July 2010. http://www.nuffieldtrust.org.uk/publications/detail.aspx? id $=145$ PRid $=714$

[3] S.F. Jencks, M.V. Williams, and E.A. Coleman, E.A. Rehospitalizations among patients in the Medicare fee-for Service Program. New England Journal of Medicine. 2009, 360(14), 1418-1428.

[4] Reported by CNN Money, http://money.cnn.com/2012/01/20 /smallbusiness/doctor loans/index.htm.

[5] Testimony of Gerard F. Anderson, Ph.D., Johns Hopkins Bloomberg School of Public Health, Health Policy and Management, before the Senate Special Committee on Aging, The Future of Medicare: Recognizing the Need for Chronic Care Coordination, Serial No. 110-7, pp. 19-20 (May 9, 2007). 